\title{
Communication
}

\section{Selective Reduction of Dimedone}

\section{Ulla Létinois* and Werner Bonrath}

DSM Nutritional Products Ltd., Research and Development, P.O Box 2676, CH-4002 Basel; E-mail: werner.bonrath@dsm.com

* Author to whom correspondence should be addressed: E-mail: ulla.letinois @dsm.com; Tel.: +41 61 815 8736, Fax: +41 618158650

Received: 30 March 2009/Accepted: 13 May 2009 / Published: 14 May 2009

\begin{abstract}
The selective hydrogenation of dimedone (1) to the corresponding monoketone 2 over palladium and Amberlyst $15^{\circledR}$ is reported. The product is a synthetic building block for the fragrance and pharmaceutical industry. Advantages of the new catalytic procedure are the high catalyst activity and selectivity, less by-product formation, avoidance of the presence of acid, and consequently, less salt formation due to the omission of a neutralization step. Using a substrate/catalyst ratio of $>100$ compound 2 can be synthesized in $97 \%$ yield at full conversion. Recycling of the catalyst several times has been shown to be feasible without any detectable decrease in selectivity.
\end{abstract}

Keywords: heterogeneous catalysis; ion exchange resins; selective hydrogenation; 1,3-diketones

\section{Introduction}

In the area of fine chemicals synthesis, research and development aiming at efficient catalytic procedures is one of the main topics in academia and industry [1]. Heterogeneously catalyzed hydrogenation reactions fulfill the criteria of Green Chemistry in terms of atom economy and waste formation [2]. An important hydrogenation reaction in the synthesis of intermediates for the flavors and fragrance industry is the selective hydrogenation of dimedone (1) to 3,3-dimethylcyclohexanone (2). The ketone 2 can be used for the synthesis of 1-(3,3-dimethyl-1-cyclohexen-1-yl)-4-penten-1-one (3), which has a woody, green odor and is widely used as perfuming and/or odor-modifying agent as well as flavoring and/or taste-modifying ingredient (Scheme 1) [3,4]. 
Scheme 1. Selective reduction of dimedone (1) for the synthesis of 1-(3,3-dimethyl-1cyclohexen-1-yl)-4-penten-1-one (3).<smiles>CC1(C)CC(=O)CC(=O)C1</smiles>

1

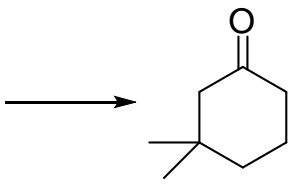

2

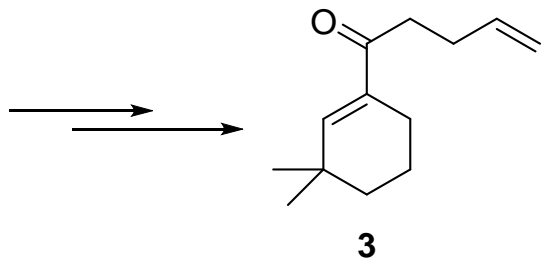

3

For the hydrogenation of dimedone (1) to 3,3-dimethylcyclohexanone (2) several two-step protocols are described in literature, for example the transformation of dimedone to an enol triflate followed by hydrogenation over $\mathrm{PtO}_{2}$ [5]. The preparation of the triflate is very expensive, requires corrosive conditions and is not atom economic at all. The reduction of $\mathbf{1}$ over nickel alloy to the saturated alcohol, followed by subsequent oxidation to $\mathbf{2}$ with dichromate in sulphuric acid as described by Champagne et al. is also not applicable at industrial scale due to the highly toxic and corrosive conditions [6].

The only one-step reduction of dimedone (1) to 2 was reported by Cormier. He obtained 3,3dimethylcyclohexanone (2) in 69-73\% yield (98-99\% purity) by Pd-catalyzed medium-pressure hydrogenation of dimedone (1) in a solvent mixture of concentrated $\mathrm{H}_{2} \mathrm{SO}_{4}$ and propionic acid [7].

For a potential industrial application it was necessary to find suitable reaction conditions for the reduction of dimedone (1) to 3,3-dimethylcyclohexanone (2) with high selectivity in one step with no or low waste formation and in the absence of any strongly oxidative (or corrosive) reagents and halides. In the present communication we describe the highly selective and efficient synthesis of 2 by hydrogenation of $\mathbf{1}$ using heterogeneous catalysis over palladium supported on the ion exchange resin Amberlyst $15^{\circledR}$ in order to circumvent the described drawbacks.

\section{Results and Discussion}

In an extensive screening of the hydrogenation of $\mathbf{1}$ to $\mathbf{2}$ we compared palladium as catalyst on various supports in various solvents. Selected results are summarized in Table 1.

Table 1. Selected screening results of the hydrogenation of $\mathbf{1}$ to 2.

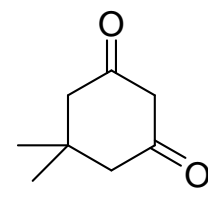

1

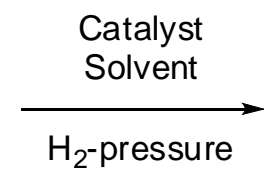

-pressure

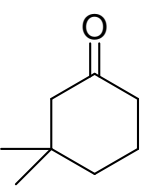

2

\begin{tabular}{|c|c|c|c|c|c|}
\hline Entry & Solvent & Catalyst & $\begin{array}{c}\text { p } \\
{[\text { bar] }}\end{array}$ & $\begin{array}{c}\text { Yield of 2 } \\
\text { [GC wt \%] }\end{array}$ & $\begin{array}{c}\Sigma^{*} \\
\text { By- } \\
\text { products }\end{array}$ \\
\hline 1 & Propionic acid & $5 \% \mathrm{Pd} / \mathrm{C}$ & 10 & 89 & 7.4 \\
\hline 2 & Acetic acid+5\% $\mathrm{H}_{2} \mathrm{SO}_{4}$ & $5 \% \mathrm{Pd} / \mathrm{C}$ & 2 & 87 & 5.2 \\
\hline 3 & Isopropanol & $5 \% \mathrm{Pd} / \mathrm{C}$ & 2 & 89 & 11 \\
\hline
\end{tabular}


Table 1. Cont.

\begin{tabular}{|c|c|c|c|c|c|}
\hline 4 & $\begin{array}{c}\text { Isopropanol +5\% } \\
\mathrm{H}_{2} \mathrm{SO}_{4}\end{array}$ & $5 \% \mathrm{Pd} / \mathrm{C}$ & 2 & 88 & 6 \\
\hline 5 & Methanol & $5 \% \mathrm{Pd} / \mathrm{C}$ & 2 & 83 & 15 \\
\hline 6 & $\begin{array}{c}\text { Isopropanol }+5 \% \\
\mathrm{H}_{2} \mathrm{SO}_{4}\end{array}$ & $5 \% \mathrm{Pd} / \mathrm{Al}_{2} \mathrm{O}_{3}$ & 2 & 70 & 12 \\
\hline 7 & Isopropanol & $5 \% \mathrm{Pd} / \mathrm{Al}_{2} \mathrm{O}_{3}$ & 2 & 14 & 45 \\
\hline 8 & $\begin{array}{c}\text { Isopropanol + 5\% } \\
\mathrm{H}_{2} \mathrm{SO}_{4}\end{array}$ & $5 \% \mathrm{Pd} / \mathrm{SiO}_{2}$ & 2 & 84 & 8 \\
\hline 9 & Isopropanol & $5 \% \mathrm{Pd} / \mathrm{SiO}_{2}$ & 2 & 7 & 58 \\
\hline 10 & Isopropanol & $0.2-1 \% \mathrm{Pd} / \mathrm{Amb}$ rlyst $15^{\circledR}$ & 2 & 96 & 1.8 \\
\hline 11 & Methanol & $0.2-1 \% \mathrm{Pd} / \mathrm{Amberlyst} 15^{\circledR}$ & 2 & 97 & 1.3 \\
\hline $12^{* * *}$ & Methanol & $0.2-1 \% \mathrm{Pd} / \mathrm{Amberlyst} 15^{\circledR}$ & 2 & 97 & 1.2 \\
\hline
\end{tabular}

In the cases where $\Sigma$ of by-products and yield of 2 do not give $100 \%$, the reaction did not go to complete conversion.

${ }^{* * *}$ Scale-up.

In the beginning, we used the conditions described by Cormier [7]: Propionic acid and acetic acid as solvents applied in the hydrogenation over palladium on charcoal led to an acceptable yield of 2 of almost 90\% (entries 1 and 2). However, several by-products were identified (Figure 1): the overreduced alcohol 4, various aldol condensation products, e.g. 5, and the propyl ester $\mathbf{6}$.

Figure 1. Frequently encountered by-products in the reduction of $\mathbf{1}$ to $\mathbf{2}$ in propionic acid.

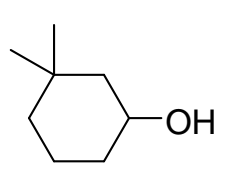

4

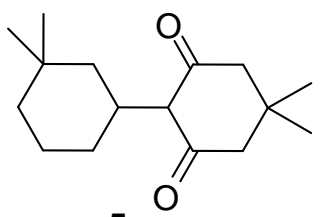

5

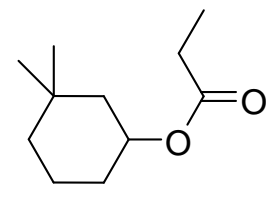

6

The saturated alcohol 4 was the major by-product. We found out that the purification of 2 by distillation is difficult in the presence of alcohol 4, as both compounds have very similar boiling points [bp (2) $180^{\circ} \mathrm{C}$; bp (4) $185^{\circ} \mathrm{C}$ at 1 bar]. Moreover, carrying out the experiments in the carboxylic acid solution in a steel autoclave led to visible corrosion of the reactor walls.

The hydrogenation over $\mathrm{Pd} / \mathrm{C}$ in isopropanol without addition of acid gave a similar yield of $89 \%$, but again also a substantial amount of the saturated alcohol 4 (entry 3). When acid was added to the reaction over $\mathrm{Pd} / \mathrm{C}$ in an alcoholic solvent, the amount of $\mathbf{4}$ as by-product decreased from 11 to $6 \%$, but the conversion of the starting material was not complete (entry 4).

When palladium on supports like silica or alumina was used, the hydrogenation of $\mathbf{1}$ in isopropanol with $\mathrm{H}_{2} \mathrm{SO}_{4}$ led to lower yields, compared to the experiments with $\mathrm{Pd} / \mathrm{C}$ (entries 6 and 8 vs. entry 4). In the absence of acid the reactions over $\mathrm{Pd} / \mathrm{SiO}_{2}$ and $\mathrm{Pd} / \mathrm{Al}_{2} \mathrm{O}_{3}$ led to even lower yields (entries 7 and 9). The experiments show clearly that the presence of acid is beneficial for the hydrogenation of $\mathbf{1}$ to $\mathbf{2}$ in terms of selectivity and yield of $\mathbf{2}$. However, as already discussed, the use of strongly acidic conditions rules out the application of the reaction in standard steel equipment, requires glass lined reactors and is expensive on an industrial scale. 
We therefore turned our attention to the use of a solid acid, e.g. ion exchange resins like Amberlyst $15^{\circledR}$. The catalytic system of palladium and Amberlyst $15^{\circledR}$ provides a perfectly suitable combination for heterogeneous hydrogenation under acidic conditions. Amberlyst $15^{\circledR}$ is a strongly acidic macroreticular cation exchange resin used as a heterogeneous acid catalyst and suitable for nonaqueous catalysis. The hydrogenation of $\mathbf{1}$ in isopropanol over Amberlyst $15^{\circledR}$ and palladium furnished a very high yield of 2 and less than $2 \%$ of by-products (entry 10). The replacement of isopropanol by methanol delivered even higher yield and only $1.3 \%$ of by-products (entry 11). We applied this protocol to a reaction at larger scale (scale-up factor 100) and were pleased to find out, that the reaction is easily scalable (entry 12 ).

We then tested if the catalyst-system can be recycled. After an experiment, the Amberlyst $15^{\circledR}$ with the palladium was filtered off, rinsed once with methanol and used for the next run. The results are illustrated in Figure 2.

Figure 2. Yield and selectivity of $\mathbf{2}$ during recycling experiments.

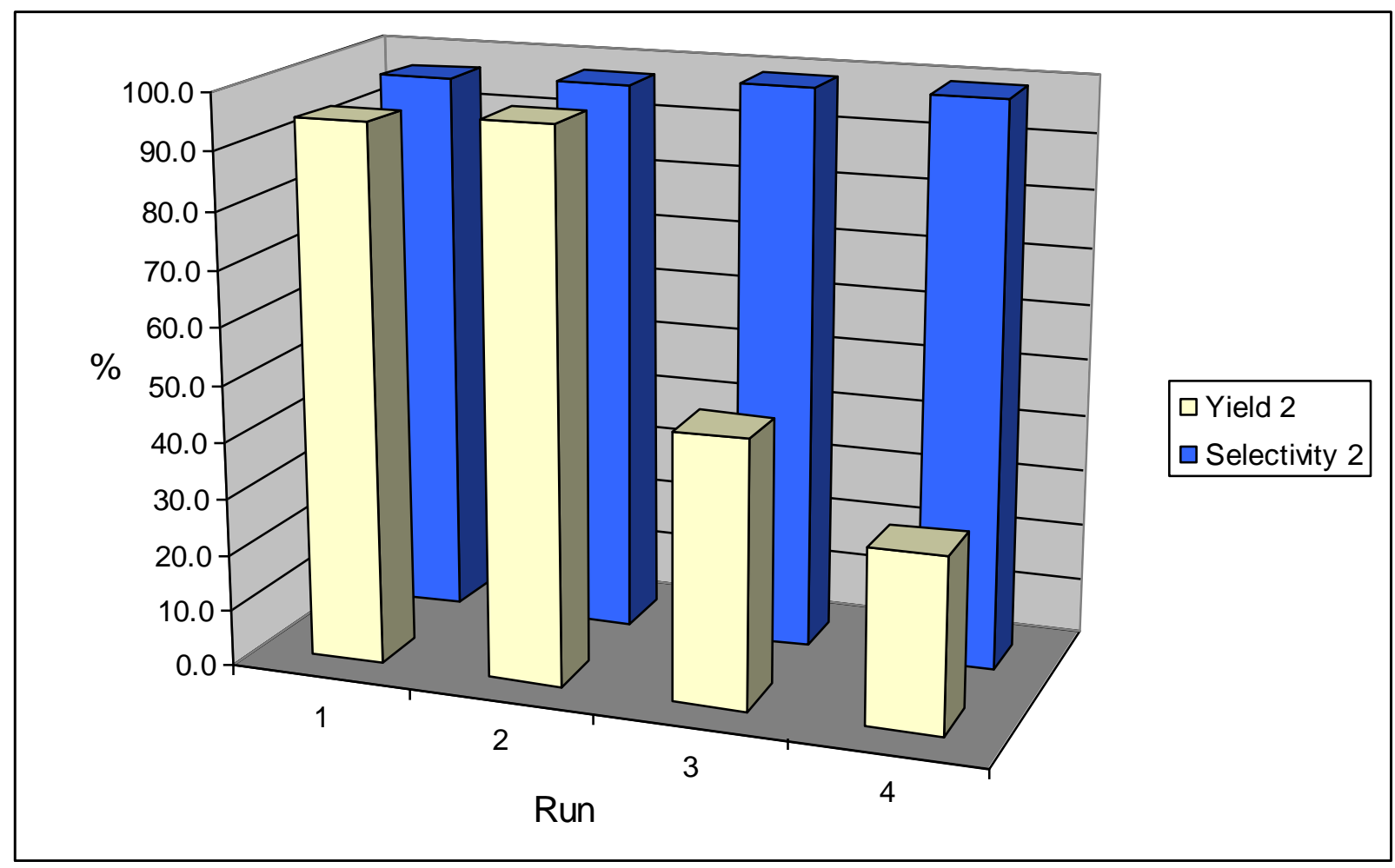

During the first two runs, the yield of 2 remained high. The third and the fourth run delivered a decreased yield, but the selectivity remained exceptionally high. We suspected that the activity of the catalyst might have dropped due to leaching of palladium from the support into the solution. Therefore, samples of the final reaction mixture were analysed after filtration of the catalyst. Elementary analysis showed that $0.01 \%$ of palladium had leached into the solution. We do not think that the decrease in activity is due to this marginal amount of leaching. The reasons for the decrease in activity could therefore be clogging of catalyst pores, or loss of acidity. These topics are currently under investigation.

Compared to the literature procedures (Table 1, entries 1,2) and to the hydrogenation in solvents containing catalytic amounts of acid, the hydrogenation of dimedone (1) over palladium on Amberlyst 
$15^{\circledR}$ in methanol leads to high yields and high selectivities of 2 . The reaction was easily scaled up. The catalyst was recycled up to four times. The third and the fourth run led to decreased conversion and yield, but the selectivity always remained higher than 95\%. Further investigations are ongoing to clarify the reaction mechanism.

\section{Experimental Section}

\section{General}

The catalyst was purchased from Rohm \& Haas. $\mathrm{Pd} / \mathrm{C}, \mathrm{Pd} / \mathrm{SiO}_{2}$ and $\mathrm{Pd} / \mathrm{Al}_{2} \mathrm{O}_{3}$ were purchased from Evonik. The catalysts were used without preliminary treatment. All reagents and solvents were purchased from Fluka and used without further purification. NMR spectra were recorded on a Bruker Avance $300 \mathrm{MHz}$ spectrometer $\left({ }^{1} \mathrm{H}-\mathrm{NMR}\right.$ spectra were recorded at $300 \mathrm{MHz},{ }^{13} \mathrm{C}$ spectra were recorded at $75 \mathrm{MHz}$ ), in DMSO-d $\mathrm{d}_{6}$ using TMS as internal standard. Chemical shifts are expressed in ppm. EI-MS spectra were obtained using a Finnigan MAT TSQ-70 spectrometer at $70 \mathrm{eV}$.

\section{Hydrogenation of Dimedone (1)}

Commercially available Pd on Amberlyst $15^{\circledR}$ catalyst $(4.99 \mathrm{~g})$ was placed in a $37 \mathrm{~mL}$ autoclave. Dimedone (1, $4.38 \mathrm{~g}, 31 \mathrm{mmol})$ and methanol (15.6 g, $19.7 \mathrm{~mL})$ was added. The glass-liner was closed and stirring at $500 \mathrm{rpm}$ was started. The autoclave was flushed with 5 bar $\mathrm{N}_{2}$ and subsequently evacuated three times. The stirrer was turned off. The autoclave was pressurized with 5 bar $\mathrm{H}_{2}$ for 10 minutes for a pressure check. The pressure was released. The stirrer was turned on again to 1,000 rpm and the autoclave was heated to $85^{\circ} \mathrm{C}$ internal temperature. The autoclave was pressurized with 2 bar $\mathrm{H}_{2}$ and the stirrer was set to $1,000 \mathrm{rpm}$. The reaction mixture was stirred under 2 bar $\mathrm{H}_{2}$ at $85^{\circ} \mathrm{C}$ for 5 hours. Then the autoclave was cooled to a temperature below $25^{\circ} \mathrm{C}$ and depressurized. After flushing three times with $\mathrm{N}_{2}$ at 5 bar for 10 minutes and subsequent evacuation stirring was stopped and the autoclave was opened. The content was sucked and filtered over a $0.45 \mu \mathrm{m}$ filter. A $30 \mu \mathrm{L}$ filtered sample was diluted with $1 \mathrm{~mL}$ of methanol and $5 \mathrm{mg}$ of $\mathrm{NaHCO}_{3}$ and then analyzed by GC. The total yield of 3,3-dimethylcyclohexanone (2) was $96 \%$ with a selectivity of $97 \%$. The catalyst was immediately placed again in a $37 \mathrm{~mL}$ glass liner and the same procedure was repeated with fresh dimedone (1) and methanol. The yield of 3,3-dimethylcyclohexanone (2) was 96\% with a selectivity of 97\%. This was again repeated twice (see the results in Figure 2). The selectivity was better than $90 \%$ for four cycles. Though the yield was rather low in cycles 3 and 4, the non-reacted starting material could be recycled, so that there was no loss in starting material. Characterization of 2: ${ }^{1} \mathrm{H}-\mathrm{NMR}$ : $\delta=2.18\left(\mathrm{t}, 2 \mathrm{H},{ }^{3} \mathrm{~J}=6.78 \mathrm{~Hz}, \mathrm{C}(6) H_{2}\right), 2.08\left(\mathrm{~s}, 2 \mathrm{H}, \mathrm{C}(2) H_{2}\right), 1.77\left(\mathrm{~m}, 2 \mathrm{H}, \mathrm{C}(5) H_{2}\right), 1.52(\mathrm{t}, 2 \mathrm{H}$, $\left.{ }^{3} \mathrm{~J}=5.66 \mathrm{~Hz}, \mathrm{C}(4) H_{2}\right), 0.89\left(6 \mathrm{H}, \mathrm{s}, \mathrm{CH}_{3}\right) ;{ }^{13} \mathrm{C}-\mathrm{NMR}: \delta=210.8(\mathrm{Cl}) ; 54.0(\mathrm{C2}), 40.1$ (C6), 37.1 (C4), $35.6(\mathrm{C3}), 28.2\left(\mathrm{CH}_{3}\right), 22.0(\mathrm{C} 5) . \mathrm{IR}\left[\mathrm{cm}^{-1}\right]: 2953(\mathrm{~s}), 2873(\mathrm{~m}), 2850(\mathrm{~m}), 1708$ (vs). MS (EI) m/z: $126\left[\mathrm{M}^{+}\right], 111\left[\mathrm{M}^{+}-\mathrm{CH}_{3}\right], 83\left[\mathrm{M}^{+}-\left(\mathrm{CH}_{3}+\mathrm{CO}\right)\right]$. 


\section{Conclusions}

In conclusion, we report here the successful use of the combination of Pd and Amberlyst $15^{\circledR}$ for the selective hydrogenation of dimedone (1) to 3,3-dimethylcyclohexanone (2). Advantages of the new catalytic procedure are the high catalyst activity and selectivity, less by-product formation, avoidance of the need for presence of acid, and less salt formation due to omission of a neutralization step. Using a substrate-to-catalyst ratio of $>100,2$ can be synthesized in $97 \%$ yield at full conversion. Recycling of the catalyst several times has been shown to be feasible without any decrease in selectivity. We were thus able to find halogen-free and non-corrosive conditions for the hydrogenation of $\mathbf{1}$ which leads to 2 in high yield and selectivity.

\section{Acknowledgements}

Hajo Lehmann is kindly acknowledged for his help with the hydrogenation experiments.

\section{References}

1. Bonrath, W.; Netscher, T. Catalytic processes in vitamins synthesis and production. Appl. Catal. A: General 2005, 280, 55-73.

2 Sheldon, R.A. Selective catalytic synthesis of fine chemicals: opportunities and trends. J. Mol. Catal. A: Chemical 1996, 107, 75-83.

3. Kraft, P.; Bajgrowicz, J.A.; Denis, C.; Frater, G. Odds and trends: recent developments in the chemistry of odorants. Angew. Chem Int. Ed. 2000, 39, 2980-3010.

4. Morris, A.F.; Naef, F.; Snowden, R.L. Dynascone: the ultimate captive. Perfumer \& Flavorist 1991, 16, 33-35.

5. Garcia Martinez, A.; Martinez Alvarez, R.; Madueno Casado, M.; Subramanian, L.R.; Hanack, M. Studies on the reduction of cyclic 1,3-diketones via their triflates. Tetrahedron 1987, 43, 275-279.

6. Champagne, J.; Favre, H.; Vocelle, D.; Zbikowski, I. Double enolization of 3,3dimethylcyclohexanone. Can. J. Chem. 1964, 42, 212-222.

7. Cormier, R.A. A convenient synthesis of 3,3-dimethylcyclohexanone. Synth. Commun. 1981, 11, 295-298.

(C) 2009 by the authors; licensee Molecular Diversity Preservation International, Basel, Switzerland. This article is an open-access article distributed under the terms and conditions of the Creative Commons Attribution license (http://creativecommons.org/licenses/by/3.0/). 